\title{
Avaliação docente no Ensino Híbrido: Estudo de Revisão no Portal de Periódicos da CAPES
}

\section{Teacher evaluation in Blended Learning: A Review on the "Portal de Periódicos da CAPES"}

\section{LEMOS, Felipe Costa;}

Mestre em Ensino de Ciências pela UFRPE (SEDE) e Graduado em Licenciatura em Química pela UAST/UFRPE. E-mail: felipecostalemos@gmail.com

ALMEIDA JR, Pedro Lemos.

Doutor em Química pela UFPB. Professor do IF Sertão - Campus Salgueiro. E-mail: plemos23@hotmail.com

\section{RESUMO}

Este artigo propõe a realização um estudo de revisão, do tipo estado da arte, voltado às estratégias utilizadas para avaliar o trabalho docente no ensino híbrido $(\mathrm{EH})$, a partir de artigos disponíveis no Portal de Periódicos CAPES entre 2010 e 2020. Foram analisados 44 trabalhos, dos quais, após leitura na Íntegra dos artigos, 18 foram selecionados por apresentarem a aplicação de propostas utilizando o EH. Sobre a avaliação do trabalho e habilidades docentes, foram percebidos que apenas 2 artigos levantaram essa análise. Nesses artigos, os pesquisadores comentaram a respeito das respostas dos alunos (Ref. A8), e investigaram a percepção dos alunos em relação ao perfil do professor e da metodologia utilizada com base em critérios bem definidos (Ref. A10). Em relação às habilidades docentes, foram verificadas poucas referências à formação e planejamento docente e a interação professor-aluno. A partir do estudo realizado, pode ser constatado um baixo número de pesquisas desenvolvidas no Brasil, nos últimos dez anos, voltadas para avaliar o trabalho docente na perspectiva do Ensino híbrido.

Palavras-Chave: Ensino Híbrido, trabalho docente, avaliação e planejamento.

\section{ABSTRACT}

This paper aims to conduct a state-of-the-art review, concerning teacher evaluation strategies in Blended Learning (BL), based on research papers on Portal de Periódicos CAPES between 2010 and 2020. In this study, 44 papers were analyzed and 18 were selected as BL applications. Only two articles raise teacher skills and strategy evaluation. In these articles, the researchers commented about the student's answers (Ref. A8), and student's perceptions about teacher profile and the methodology used based on well-defined criteria (Ref. A10). Regarding teacher skills, few references about teacher's formation, formation and planning, and teacher-student interaction were noticed. Based on this study, can be analyzed a low amount of research developed in Brazil, concerning evaluating teaching work in blended learning in the last ten years.

keywords: Blended Learning, teaching work, evaluation, and planning.

\section{Considerações Iniciais}

O espaço de atuação docente é um enorme cenário de possibilidades. Ao atuar nesses ambientes, é necessária uma formação cada vez mais exigente na tentativa de facilitar a construção de conhecimentos pelos discentes a partir da aplicação das mais diversas metodologias de ensino. Não basta aplicar estratégias de ensino reconhecidas como promissoras, o docente precisa desenvolver habilidades que o torne capaz de se autoavaliar e de buscar alternativas para aprimorar a sua formação frente a novas e complexas alternativas.

Um exemplo dessas estratégias promissoras é o Ensino híbrido (EH), constituído de uma estratégia de ensino na qual atividades são planejadas e aplicadas de modo a combinar recursos e métodos presenciais e online. Além disso, Staker e Horn (2012) apontam que essa estratégia prevê 
LEMOS, F. C.; ALMEIDA JR, P. L. (2020) Avaliação docente no Ensino Híbrido

um acompanhamento do estudante pelo professor, em relação a seu tempo e ritmo de estudos, assim como, estratégias de acompanhamento do aluno e trajetórias de estudos adotadas.

No que se refere a história do Ensino Híbrido, Passos (2018) aponta que no início do século XXI o termo blended learning, ou em português ensino híbrido, emergiu como uma nova tendência de modelo de ensino e estilo de aprendizagem. Já em 2020, no momento histórico atual, quando se discutem possíveis estratégias em meio à pandemia da COVID-19, é essencial distinguir o Ensino Híbrido das modalidades de Ensino a Distância (EaD) e Ensino Semipresencial, para que possa ser escolhido o melhor modelo a ser trabalhado, considerando as particularidades das diferentes turmas e níveis de ensino.

Embora ainda não exista um consenso sobre as diretrizes a serem seguidas ao aplicar o Ensino Híbrido (EH), diferente das demais formas de ensino citadas, há uma preocupação com a personalização (voltada para elaborar, por exemplo, atividades presenciais ou online que facilitem a aprendizagem para diferentes perfis de estudantes), bem como com asas etapas de ensino online as quais não precisam obrigatoriamente ser distante da figura física do docente. Além disso, o processo de aprendizagem integra as modalidades de ensino presencial e online sem que as etapas de ensino presencial estejam ligadas apenas às atividades complementares.

No EH, o professor deixa de ser o único detentor do conhecimento e protagonista do processo de aprendizagem do discente, para se comportar como um facilitador. Sob essa perspectiva, Silva (2017), aponta que ao trabalhar com o EH, o professor deve traçar cuidadosamente suas metas e organizar as atividades, para que o aluno possa agir de forma autônoma, mas que de maneira alguma se sinta desamparado. Todas as atividades precisam ser bem direcionadas e contar com material de apoio para dar suporte às necessidades que forem surgindo.

Desta forma, a proposta para o professor deve ser: de orador para facilitador; de generalista para especialista; de estrutura de grupos fixos para estratégias mais dinâmicas de agrupamento; deixar de ser quem explica, conforme a necessidade, apenas intervindo no momento certo; deixar de focar no conteúdo apenas, para concentrar-se em conteúdo, habilidades e na postura dos alunos (MIRANDA E COLABORADORES, 2020, p. 15).

É importante perceber que ao utilizar o EH com grupos heterogêneos, o professor não pode ser transformado em um tutor em tempo integral. Além disso, as atividades realizadas fora da escola com o acompanhamento online do professor serão apenas uma parte do processo de aprendizagem. O termo "híbrido" deve ser condicionado a um equilíbrio entre a sala de aula física e o ensino online que dependerá do perfil do estudante ou da turma. Desta forma, o ensino presencial continua sendo imprescindível.

Sabendo desses cuidados a serem tomados, partindo da importância de avaliar o papel docente ao utilizar o EH e voltada à atenção para as habilidades docentes, surgiu necessidade de desenvolver esta pesquisa. A partir da análise das publicações, ao responder à seguinte questão norteadora da pesquisa: quais são as estratégias utilizadas para avaliar o trabalho docente no Ensino Híbrido e quais habilidades docentes emergem nas discussões dos resultados das pesquisas disponíveis no Portal de Periódicos CAPES?

$\mathrm{Na}$ busca para responder essa questão, têm-se como objetivo principal realizar um estudo de 
LEMOS, F. C.; ALMEIDA JR, P. L. (2020) Avaliação docente no Ensino Híbrido

revisão, do tipo estado da arte, voltado para as estratégias utilizadas para avaliar o trabalho docente no Ensino híbrido, a partir das pesquisas disponíveis no Portal de Periódicos CAPES no intervalo de dez anos, correspondentes de Maio de 2010 a Maio de 2020. A opção pela pesquisa nessa base de dados pode ser justificada pela sua relevância ao permitir o acesso a periódicos de todas as regiões e das diversas áreas do conhecimento. Vale salientar que para a investigação aqui realizada não foi definido nível ou área de ensino.

\section{O ENSINO HÍBRIDO E A IMPORTÂNCIA DAS HABILIDADES DO PROFESSOR EM SEUS MODELOS}

O ensino híbrido é uma abordagem pedagógica que combina atividades presenciais com atividades realizadas online por meio das tecnologias digitais de informação e comunicação (TDIC). Essa abordagem se apresenta como uma das tendências mais importantes para a educação do século XXI (CANDIDO JUNIOR, 2019, p. 43).

Ao aplicar essa abordagem em sala de aula, existem diversas formas ou modelos para inserir essas tecnologias digitais. Na Figura 1, apresentada a seguir, apontaremos quatro modelos que, segundo Horn e Staker (2015), os cursos que trabalham com o ensino híbrido costumam se enquadrar. São eles: Rotação, Flex, À la Carte e Virtual Enriquecido.

Figura 1. Modelos de Ensino híbrido

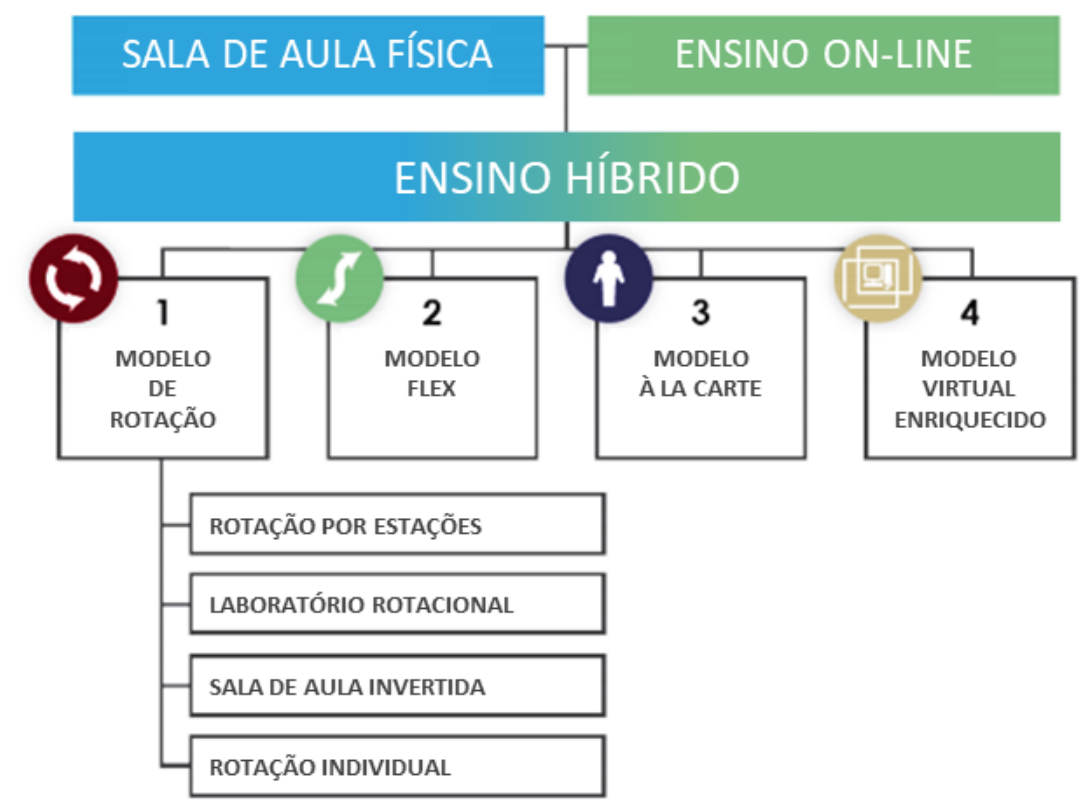

(Adaptado de: Horn e Staker, 2015).

Brevemente, esses modelos podem ser descritos como:

1 - Modelo de rotação: Propõe o rodízio entre o ensino online e o ensino presencial, em que o aluno alterna entre as duas modalidades de aprendizagem (KRAVISKI, 2019, p. 33).

Esse modelo está dividido em outros quatro subgrupos. 0 primeiro, Rodízio por Estações, é aquele onde, segundo Horn e Staker (2015), os estudantes utilizam o modelo de rotação em uma sala 
LEMOS, F. C.; ALMEIDA JR, P. L. (2020)

Avaliação docente no Ensino Híbrido

de aula ou grupo de salas de aula, sendo que pelo menos uma das estações emprega os recursos de ensino online. Nesse modelo, o grupo interage com o professor buscando tirar suas dúvidas e ampliar os conhecimentos. 0 segundo subgrupo é o Laboratório Rotacional, no qual o aluno circula em diferentes espaços dentro do campus, sendo um deles o laboratório no qual ele realiza atividades online, ou laboratórios para o desenvolvimento de práticas específicas. (VALENTE, 2014, p. 85). Já o terceiro subgrupo é o Sala de Aula Invertida, no qual os estudantes veem o conteúdo antecipadamente em suas residências para que, em sala, as dúvidas sejam trabalhadas e possam interagir com mais liberdade com o professor e demais aprendizes (CONSERVA e COSTA, 2020, p. 238). Por fim, o último subgrupo, o modelo de Rotação Individual, difere dos outros modelos de rotação porque, em essência, trabalha com a personalização do ensino. Nesse modelo, cada aluno tem um roteiro individualizado e, não necessariamente, participa de todas as estações ou modalidades disponíveis. (BARION e MELLI, 2017, p. 599).

2 - Modelo Flex: É um tipo de modelo no qual o ensino online é a espinha dorsal do aprendizado do aluno, mesmo que ele o direcione para atividades offline em alguns momentos. Os estudantes seguem um roteiro fluído e adaptado individualmente nas diferentes modalidades de ensino, e o professor responsável está na mesma localidade (VERGANA E COLABORADORES, 2018, p. 888). Nesse tipo, a localidade pode ser, por exemplo, um laboratório de informática no qual serão disponibilizados os computadores e, os professores atuarão tirando dúvidas, agindo como tutores, ou levando os estudantes para espaços convencionais nos quais ocorrerá o ensino presencial. É preciso reforçar que o papel de tutor do professor aqui mencionado está condicionado à capacidade do estudante de construir o conhecimento a partir das ferramentas utilizadas.

3 - Modelo à La Carte: Nesse tipo de modelo, o professor define os objetivos a serem estudados e fornece suporte, quando necessário. No entanto, é o estudante que se responsabiliza em organizar os estudos, podendo inclusive ser totalmente online (SCHIEHL e GASPARINI, 2016, p. 4). Aqui há uma aproximação com o EaD a partir do momento que o estudante opta por fazer o curso integralmente fora da escola e o docente atua como tutor. No entanto, esse curso é apenas uma parte do processo de EH. Nas outras partes, há o ensino presencial.

4 - Modelo Virtual Enriquecido: É o modelo semipresencial de ensino no qual o aluno terá seu ensino orientado, organizado juntamente com o professor, realizando atividades online, porém com a necessidade de ter, periodicamente, momentos presenciais com seus pares. (ANTONELLO NETO, 2017, p.32). Esse modelo, embora se aproxime de um Ensino semipresencial, depende do perfil do estudante. Caso o estudante consiga construir a aprendizagem a partir do ensino online, ele poderá optar por menos momentos presenciais, mas esses continuarão sendo imprescindíveis para a construção do conhecimento. No entanto, se houver dificuldade de aprendizagem de maneira não presencial pelo aluno, haverá a possibilidade de adequar esse perfil com o ensino presencial e online.

Ao estudar sobre esses modelos, é interessante destacar a complementação da figura do professor que passa de único "detentor" do conhecimento, para um mediador preocupado com a personalização do ensino. Se antes o professor já era mediador, mas com um único modelo de ensino para todas as turmas e estudantes, no $\mathrm{EH}$, ao considerar os conhecimentos prévios, reconhecer as estratégias de aprendizagem que facilitam a construção do conhecimento e as motivações e 
LEMOS, F. C.; ALMEIDA JR, P. L. (2020)

Avaliação docente no Ensino Híbrido

limitações de cada estudante. 0 o professor poderá trabalhar a valorização e personalização do ensino. 0 estudante nessa perspectiva, diferente de um perfil autodidata, constrói o conhecimento a partir das ferramentas e da orientação do professor, e reconhece os seus limites. Sobre isso, Cerutti e Melo (2017) acrescentam que o EH prevê a mediação do professor no processo de ensino-aprendizagem de forma dinâmica, reforçando a atitude investigativa do aluno, de forma que, de maneira conjunta, trabalhem em prol da construção do conhecimento.

Nesse sentido, Lima e Moura (2015) acrescentam que a ação docente no EH é voltada para a tutoria de aprendizado, sendo capaz de identificar problemas e agir com foco em individualizar e personalizar o ensino. Essa mediação é uma habilidade pouco explorada na prática docente, e a tecnologia permite ao professor passar instrução online e trabalhar propostas inovadoras em sala. Outras habilidades inerentes ao professor no EH são apontadas por esses autores ao destacar que:

Se o necessário é a instrução, o professor deve selecionar ou criar um vídeo adequado; se o objetivo é a interatividade, ele pode escolher um game ou simulador; e se a meta é avaliar, ele deve escolher uma ferramenta eficiente no levantamento de dados para transformar feedback em orientação educacional. Em um planejamento de aula eficiente, devem ser escolhidas as ferramentas e a forma de utilizálas, bem como definir o papel do aluno e do professor. (LIMA e MOURA, 2015, p. 94).

Ao realizar atividades voltadas para essa metodologia híbrida, modificam-se as habilidades do professor. Nessa perspectiva, Hoffmann (2016) aponta que o docente precisa de planejamento direcionado no qual saberá precisamente qual será seu papel em cada momento do processo. Ao utilizar o EH, é possível que o professor produza seus próprios vídeos, ou ainda selecione aquilo que precisa ensinar em vídeos já disponíveis e no decorrer da aula, torne-se um tutor, auxiliando seus educandos individual ou até mesmo em grupos.

\section{Materiais e Métodos}

0 presente trabalho se configura como um estudo de revisão, do tipo estado da arte, estruturado como parte de uma pesquisa voltada para as habilidades necessárias ao docente em meio ao planejamento e aplicação do Ensino Híbrido em suas aulas. Partindo desse estado da arte pretendemos responder as questões da pesquisa e avançar na temática da importância da avaliação docente, incluindo a reflexão sobre as habilidades desses sujeitos dentro do EH no trabalho com, por exemplo, ferramentas digitais.

Sobre o estado da arte, ao escolher esse tipo de pesquisa na tentativa de alcançar nossos objetivos, concorda-SE com Angelucci e colaboradores (2004), quando defendem a multiplicidade da importância de balanços periódicos da bibliografia vigente numa determinada área de pesquisa. Esse tipo de revisão pode detectar teoria e método dominantes; pôr em relevo aspectos do objeto de estudo que se esboçam nas entrelinhas das novas pesquisas; revelar em que medida a pesquisa recente relaciona-se com a anterior e elaborar uma trama que permite avançar na compreensão do objeto de estudo pela via do real acréscimo ao que já se conhece ou da superação de concepções anteriores.

Um dos caminhos metodológicos utilizados ao realizar uma revisão de estado da arte é aquele apresentado por Palanch e Freitas (2015), que apontam os seguintes passos: (i) definição dos 
LEMOS, F. C.; ALMEIDA JR, P. L. (2020)

Avaliação docente no Ensino Híbrido

descritores para direcionar a busca das informações; (ii) localização dos bancos de pesquisas (artigos, teses, acervos etc.); (iii) estabelecimento de critérios para a seleção do material que comporá o corpus do estudo; (iv) coleta do material de pesquisa; (v) leitura das produções, com elaboração de sínteses preliminares; (vi) organização de relatórios envolvendo as sínteses e destacando tendências do tema abordado; e (vii) análise e elaboração das conclusões preliminares.

Nesse estudo, buscando atender aos objetivos e já previamente definido o banco de dados como o Portal de Periódicos CAPES, o termo de busca como "Ensino híbrido" e o período a ser pesquisado (intervalo de 10 anos correspondente de maio de 2010 a maio de 2020), optou-se pelo caminho apresentado a seguir:

1- Ler cada uma das publicações encontradas, a partir do termo de busca e período escolhido, e selecionar todas as que apresentaram a aplicação de propostas utilizando o ensino híbrido em salas de aula;

2- Apresentar o resultado da etapa anterior a partir de uma tabela contendo título, ano de publicação, autores e uma referência (Ref. A1, por exemplo) voltada a cada pesquisa para uma posterior citação; 3 - Realizar uma segunda leitura com o foco para a metodologia e resultados, buscando destacar o modelo de EH utilizado, o perfil de análise da pesquisa e a forma com a qual as pesquisas selecionadas têm avaliado o trabalho docente. Dentro desse perfil de análise serão apresentados o público-alvo da pesquisa (incluindo ano, componente curricular e curso) e as técnicas utilizadas para coleta e análise de dados.

4 - Apresentar novamente os trabalhos selecionados a partir de uma tabela contendo a referência e o perfil de análise das publicações.

5 - Por último, apresentar e discutir quais modelos de EH foram mais utilizados, se/como essas pesquisas têm avaliado o trabalho docente e quais habilidades docentes tem emergido.

\section{Resultados e discussão}

Os resultados das etapas a partir da busca do termo "Ensino híbrido" no o Portal de Periódicos CAPES utilizando um intervalo de maio 2010 até maio de 2020 (10 anos) são apresentadas a seguir.

Primeiramente, a partir da busca no período estipulado, foram encontradas 44 publicações. Dentre as quais após uma leitura inicial, foram selecionados 18 trabalhos que traziam em sua estrutura a aplicação de propostas, utilizando o ensino híbrido em salas de aula. No Quadro 1, seguindo as etapas apontadas no tópico anterior, esses trabalhos são apresentados.

Quadro 1 - Artigos Selecionados

\begin{tabular}{|c|c|c|c|}
\hline Ref. & Título & Revista - Ano & Autor (es) \\
\hline A1 & $\begin{array}{c}\text { O Ensino Híbrido da eletricidade } \\
\text { utilizando objetos de aprendizagem na } \\
\text { engenharia }\end{array}$ & $\begin{array}{c}\text { Caderno Brasileiro de } \\
\text { Ensino de Física - 2010 }\end{array}$ & $\begin{array}{c}\text { Siqueira, L.M.M e } \\
\text { Torres, P.L }\end{array}$ \\
\hline A2 & De mãos limpas com as tecnologias \\
digitais & Rev. SUSTINERE - 2016 & $\begin{array}{c}\text { Steinert, M.e.P; } \\
\text { Hardoim, E.L e } \\
\text { Pinto, M.P.P.R.C. }\end{array}$ \\
\hline
\end{tabular}




\begin{tabular}{|c|c|c|c|}
\hline $\mathrm{A} 3$ & $\begin{array}{l}\text { Ensino Híbrido em formação docente de } \\
\text { curso de Biologia em uma disciplina em } \\
\text { Instituição de Ensino Superior Pública }\end{array}$ & Rev. Educitec - 2016 & Santos, S.C.S. \\
\hline A4 & $\begin{array}{l}\text { Problematizando práticas de ensino e } \\
\text { aprendizagem na plataforma Moodle: } \\
\text { Aproximações com a modalidade híbrida }\end{array}$ & $\begin{array}{l}\text { Rev. EntreLínguas - } \\
2016\end{array}$ & Costa, H.B.A \\
\hline A5 & $\begin{array}{l}\text { Redes sociais e aprendizagem no ensino } \\
\text { superior: a perspectiva dos alunos sobre o } \\
\text { uso do Facebook em uma disciplina de } \\
\text { língua inglesa }\end{array}$ & $\begin{array}{l}\text { Veredas - Revista de } \\
\text { Estudos Linguísticos } \\
\qquad-2016\end{array}$ & $\begin{array}{l}\text { Rabello, C.R.L e } \\
\text { Tavares, K.C.A. }\end{array}$ \\
\hline A6 & $\begin{array}{l}\text { Leigos ou excluídos? A criação de um } \\
\text { aplicativo educacional e seu uso via } \\
\text { ensino híbrido em uma escola pública }\end{array}$ & Rev. SUSTINERE - 2017 & $\begin{array}{l}\text { Steinert, M.E.P e } \\
\text { Hardoim, E.L. }\end{array}$ \\
\hline A7 & $\begin{array}{l}\text { O Ensino Híbrido como modalidade de } \\
\text { interação ativa e reflexão crítica: relato } \\
\text { de uma experiência docente no Brasil }\end{array}$ & $\begin{array}{l}\text { Rev. Texto Livre: } \\
\text { Linguagem e Tecnologia } \\
\text { - } 2017\end{array}$ & $\begin{array}{l}\text { Pasin, D.Me } \\
\text { Delgado, H.O.K. }\end{array}$ \\
\hline A8 & $\begin{array}{c}\text { Como Significar a Aprendizagem de } \\
\text { Matemática Utilizando os Modelos de } \\
\text { Ensino Híbrido }\end{array}$ & Rev. Thema - 2018 & $\begin{array}{l}\text { Vergara, A. C. E; } \\
\text { Hinz, V. T e Lopes, } \\
\text { J. L. B. }\end{array}$ \\
\hline A9 & $\begin{array}{l}\text { Ensino Híbrido com a utilização da } \\
\text { plataforma Moodle }\end{array}$ & Rev. Thema - 2018 & $\begin{array}{l}\text { Frantz, D.S.F.S; } \\
\text { Marques, N.L,R; } \\
\text { Nunes, J.F e } \\
\text { Marques }\end{array}$ \\
\hline $\mathrm{A} 10$ & $\begin{array}{l}\text { Modelo de Ensino Híbrido: a percepção } \\
\text { dos alunos em relação à Metodologia } \\
\text { progressista x Metodologia tradicional }\end{array}$ & $\begin{array}{l}\text { Rev. Conhecimento } \\
\text { Online - } 2018\end{array}$ & $\begin{array}{l}\text { Silva, J.B; Silva, } \\
\text { D.O e Sales, G.L. }\end{array}$ \\
\hline $\mathrm{A} 11$ & $\begin{array}{l}\text { Narrativas digitais para uma } \\
\text { aprendizagem significativa no Ensino } \\
\text { Superior: qual a percepção dos } \\
\text { estudantes? }\end{array}$ & $\begin{array}{l}\text { Rev. Educação por } \\
\text { Escrito - } 2018\end{array}$ & $\begin{array}{l}\text { Nascimento, E.R; } \\
\text { Anjos, F.L.M.R; } \\
\text { Menezes, K.K.O e } \\
\text { Oliveira, G.B.L. }\end{array}$ \\
\hline $\mathrm{A} 12$ & $\begin{array}{l}\text { Testando novas metodologias de } \\
\text { aprendizagem para o ensino de } \\
\text { embriologia humana: relato de } \\
\text { experiência e percepção dos discentes }\end{array}$ & $\begin{array}{c}\text { Rev. Docência no } \\
\text { Ensino Superior - } 2018\end{array}$ & Ribeiro \\
\hline $\mathrm{A} 13$ & $\begin{array}{l}\text { Uma proposta de ensino-aprendizagem de } \\
\text { inglês para fins específicos baseada no } \\
\text { Ensino Híbrido }\end{array}$ & $\begin{array}{l}\text { Rev. EntreLínguas - } \\
2018\end{array}$ & $\begin{array}{l}\text { Sousa, Y.H; } \\
\text { Mendonça A.P e } \\
\text { Coelho, I.M.W.S. }\end{array}$ \\
\hline $\mathrm{A} 14$ & $\begin{array}{l}\text { Ensino híbrido e a construção da } \\
\text { aprendizagem dos estudantes do ensino } \\
\text { médio }\end{array}$ & $\begin{array}{l}\text { Rev. Scientia cum } \\
\text { industria - } 2019\end{array}$ & $\begin{array}{l}\text { Cembranel, C.B e } \\
\text { Scopel, J.M. }\end{array}$ \\
\hline A15 & $\begin{array}{l}\text { Aprendizagem por meio do ensino híbrido } \\
\text { na educação superior: narrando o } \\
\text { engajamento dos estudantes }\end{array}$ & $\begin{array}{l}\text { Rev. Diálogo } \\
\text { Educacional - } 2020\end{array}$ & $\begin{array}{l}\text { Nascimento, E.R e } \\
\text { Padilha, M.A.S. }\end{array}$ \\
\hline A16 & $\begin{array}{l}\text { Blended learning como estratégia de } \\
\text { engajamento no ensino superior: relato }\end{array}$ & Rev. EDaPECI - 2020 & $\begin{array}{l}\text { Wajnsztejn, M; } \\
\text { André, C.F e }\end{array}$ \\
\hline
\end{tabular}




\begin{tabular}{|c|c|c|c|}
\hline & $\begin{array}{l}\text { de uma experiência de aprendizagem } \\
\text { conectada, colaborativa e social }\end{array}$ & & Azevedo, A.B. \\
\hline A17 & $\begin{array}{l}\text { O ensino de inglês permeado pela } \\
\text { proposta de sala de aula invertida: um } \\
\text { relato de experiência didática }\end{array}$ & Rev. ETD - 2020 & $\begin{array}{l}\text { Conserva, D.P e } \\
\text { Costa, M.A.M. }\end{array}$ \\
\hline A18 & $\begin{array}{l}\text { Rotação por estações no trabalho com } \\
\text { equações do } 2^{\circ} \text { grau: uma experiência na } \\
\text { perspectiva do ensino híbrido. }\end{array}$ & Rev. EMP- 2020 & $\begin{array}{l}\text { Guimarães, D.S e } \\
\text { Junqueira, S.M.S. }\end{array}$ \\
\hline
\end{tabular}

Ao Identificar os trabalhos apresentados no Quadro 1, é possível perceber poucas publicações voltadas para apresentação de propostas de ensino híbrido. Em relação aos demais periódicos (26) não incluídos no Quadro 1, é importante apontar que se tratam de diferentes abordagens, tais como: resenhas de livros, debates teóricos sobre o ensino híbrido, publicações em mais de uma língua, entre outros.

A partir da análise da segunda leitura dos artigos e com o foco para a metodologia e resultados, foi elaborado o quadro 2 com os perfis de análise de cada uma das publicações.

Quadro 2 - Perfil de análise dos artigos selecionados

\begin{tabular}{|c|c|}
\hline Ref. & Perfil de análise \\
\hline $\mathrm{A} 1$ & $\begin{array}{l}\text { A proposta foi desenvolvida no início do segundo semestre de } 2008 \text { com quarenta e quatro } \\
\text { (44) alunos matrículados na disciplina de Eletricidade, do currículo do curso de Eng. Elétrica } \\
\text { da PUCPR. A análise foi feita a partir da aplicação de questionários aos estudantes voltados } \\
\text { para questões relacionadas à validade de se utilizar o material online como apoio ao ensino } \\
\text { presencial. }\end{array}$ \\
\hline $\mathrm{A} 2$ & $\begin{array}{l}\text { Desenvolvida em data não especificada com trinta e oito (38) estudantes das disciplinas de } \\
\text { Biologia e Química do } 2^{\circ} \text { ano do ensino médio, sendo que apenas dez participaram da coleta } \\
\text { de dados. A escola de nome não apresentada foi descrita como localizada no bairro da zona } \\
\text { norte de Cuiabá, onde atende somente ao ensino médio, regular e profissionalizante. Foi } \\
\text { realizada uma análise geral da aplicação do ensino híbrido contando parcialmente com res- } \\
\text { postas por escrito dos estudantes sobre a higienização das mãos ao longo das atividades. }\end{array}$ \\
\hline A3 & $\begin{array}{l}\text { Realizada nos anos de } 2013 \text { e } 2014 \text { com vinte e um (21) alunos matriculados na disciplina } \\
\text { Instrumentação para o Ensino de Biologia, do curso de Licenciatura em Ciências Biológicas } \\
\text { em uma IES pública não especificada. Na análise, foi observada uma descrição da aplicação } \\
\text { das atividades envolvendo o ensino híbrido e o comportamento das turmas ao longo do pro- } \\
\text { cesso. }\end{array}$ \\
\hline A4 & $\begin{array}{l}\text { Esta proposta feita em data e quantidade de alunos não especificada, nas disciplinas de } \\
\text { "Aquisição e aprendizagem do Francês como Língua Estrangeira" e "Atividades de Estágio } \\
\text { em Francês" do Curso de Letras da Faculdade de Filosofia, Letras e Ciências Humanas da } \\
\text { Universidade de São Paulo (FFLCH-USP). Ao longo do projeto foi feito um estudo reflexivo- } \\
\text { crítico das experiências de ensino realizadas na Plataforma Moodle. }\end{array}$ \\
\hline A5 & $\begin{array}{l}\text { A proposta foi desenvolvida no primeiro semestre de } 2012 \text {, com cinquenta e sete (57) alunos } \\
\text { matriculados na disciplina Inglês I, do curso de graduação em Relações Internacionais de } \\
\text { uma Universidade Federal não identificada. A análise da pesquisa contou com um questio- } \\
\text { nário aplicado aos estudantes sobre o uso do YouTube, blogs e sites de redes sociais (SRS) } \\
\text { buscando as suas percepções quanto à utilização do Facebook como espaço complementar } \\
\text { às aulas presenciais. }\end{array}$ \\
\hline
\end{tabular}


A6 A proposta desenvolvida em outubro de $2016 \mathrm{com}$ vinte e sete (27) estudantes (sendo que apenas 17 participaram de todas as análises de dados), na disciplina de biologia em uma turma de $2^{\circ}$ ano do Ensino Médio. A análise da pesquisa foi realizada via formulário aplicado aos estudantes para a avaliação: das atividades que fizeram parte das estações organizadas, do uso aplicativo e da dinâmica híbrida com foco na avaliação do aplicativo e da proposta de ensino.

A7 Realizada no segundo semestre de 2015 com vinte e oito (28) alunos matriculados na disciplina Língua Inglesa VII, do curso de Licenciatura em Letras - com habilitação em língua inglesa na PUCRS em Porto Alegre-RS. A análise contou com depoimentos falados dos alunos sobre o uso de atividades inseridas numa modalidade híbrida e de uma análise crítica e reflexiva da prática pedagógica das pesquisadoras, a partir das contribuições de autores diversos sobre a construção coletiva do conhecimento e sobre os pontos positivos da experiência docente.

A8 A proposta foi desenvolvida em 2017 com quinze (15) estudantes na disciplina de matemática do $8^{\circ}$ ano do ensino fundamental, além de três (3) professores e quatro (4) gestores da Escola de Ensino Fundamental Frederico Ozanan, da rede pública municipal de Pelotas-RS. A análise apresentou formulários direcionados aos estudantes e com relato das aulas. Dentro da análise foi avaliada a experiência do uso do Laboratório Rotacional, bem como caracterizadas as estratégias e práticas pedagógicas que devem ser abordadas no o Ensino Híbrido.

A9 Desenvolvida em maio e junho de 2018 com a turma matriculada na disciplina de Mecânica Analítica, do oitavo semestre da Licenciatura em Física no Instituto Federal Sul-rio-grandense - Campus Pelotas Visconde da Graça. A análise foi realizada a partir da aplicação de um questionário contendo duas questões discursivas voltadas para o uso de metodologia voltada para o ensino híbrido nas aulas e o tempo ideal para a duração de uma vídeo-aula.

A10 Proposta realizada no segundo semestre de 2016 em uma turma de trinta e cinco (35) alunos na disciplina de Física do primeiro ano do Ensino Médio, do curso técnico integrado em Química do Instituto Federal de Educação, Ciência e Tecnologia do Ceará (IFCE). A análise dos dados foi realizada a partir da resolução de um questionário com questões voltadas ao professor, às metodologias de ensino/aprendizagem empregadas pelos professores, à interação professor-aluno e ao processo avaliativo.

A11 A proposta desenvolvida em período não especificado com um grupo de vinte e cinco (25) estudantes matriculados no curso de extensão sobre os empregos do futuro, de um grupo de graduação da rede particular de ensino superior não especificada. Os dados da pesquisa foram coletados por meio de entrevistas individuais, de grupo focal e do diário de aprendizagem, que posteriormente passaram por uma análise de conteúdo voltada para a percepção dos estudantes de graduação da rede particular de ensino sobre o uso de narrativas digitais para uma aprendizagem significativa.

A12 A proposta em período não especificado com trinta (30) estudantes matriculados no componente curricular Embriologia Humana do, primeiro semestre do curso de graduação em Medicina da Universidade do Estado da Bahia (UNEB) em Salvador-BA, sendo descrita como relato de experiência onde descreve e avalia o emprego de metodologias ativas, em consonância com o método tradicional de ensino. A análise da pesquisa foi voltada para avaliar questionários investigativos sobre as atividades desenvolvidas no trabalho em equipe, as dificuldades encontradas e a presença, ou não, de interdisciplinaridade e aquisição de conhecimentos, com o intuito de se avaliar a eficácia das abordagens de ensino e a aprendizagem dos conteúdos.

A13 Desenvolvida no primeiro semestre acadêmico de 2017, com dezenove (19) alunos matriculados na disciplina Inglês Instrumental, em um Curso Técnico de Nível Médio em Informática de uma Instituição Federal de Ensino não especificada. A análise da pesquisa foi voltada para questionários aplicados ao público sobre questões relacionadas ao curso e a implementação da Blended English Teaching (BET). 


\begin{tabular}{|c|c|}
\hline $\mathrm{A} 14$ & $\begin{array}{l}\text { Desenvolvida a partir de 2017, aplicada nas diversas disciplinas, com quinhentos (500) estu- } \\
\text { dantes do ensino médio da Escola Estadual de Ensino Básico Abramo Pezzi, localizada na } \\
\text { cidade de Caxias do Sul, Rio Grande do Sul, sendo descrita como relato da experiência onde } \\
\text { trata da utilização da plataforma de ensino adaptativo Geekie Lab. Ao longo do artigo foram } \\
\text { apresentadas apenas as impressões dos pesquisadores sobre o uso da plataforma. }\end{array}$ \\
\hline A15 & $\begin{array}{l}\text { A proposta entre fevereiro e junho de } 2019 \text {, com cinquenta }(50) \text { estudantes dos cursos su- } \\
\text { periores de "Tecnologia em Análise e Desenvolvimento de Sistemas" e "Sistemas para Inter- } \\
\text { net", ofertados em uma faculdade filantrópica instalada na Cidade do Recife-PE. Para a } \\
\text { análise de dados, foram considerados os diários de aprendizagem dos estudantes via formu- } \\
\text { lário virtual, a escala de Veiga aplicada a questionários direcionados também ao grupo e os } \\
\text { registros videográficos de reuniões de um grupo focal com a participação de vinte e oito (28) } \\
\text { estudantes. Buscou-se conhecer o nível de engajamento dos estudantes ao longo da imple- } \\
\text { mentação do modelo híbrido. }\end{array}$ \\
\hline A16 & $\begin{array}{l}\text { Nos anos de } 2018 \text { e } 2019 \text { com alunos (número não especificado) em disciplina não especifi- } \\
\text { cada, do segundo semestre da graduação do curso de Publicidade e propaganda em uma } \\
\text { instituição de ensino superior do município de São Paulo. A análise da pesquisa foi voltada } \\
\text { para as respostas de questionários aplicados aos estudantes sobre a concepção, a implanta- } \\
\text { ção e a discussão de um formato de aula híbrida. }\end{array}$ \\
\hline $\mathrm{A} 17$ & $\begin{array}{l}\text { Proposta no segundo semestre de } 2017 \text { com vinte e dois }(22) \text { alunos de duas turmas do nível } \\
\text { pré-intermediário em uma escola de idiomas na cidade de Patos-PB. Dentro desse trabalho } \\
\text { o foco foi na descrição do relato das experiências didáticas havendo análise da metodologia } \\
\text { utilizada apenas a partir de questionamentos aplicados aos estudantes. Todos foram unâni- } \\
\text { mes em afirmar que acharam mais positivo e que "tinham gostado" da experiência e que } \\
\text { desejavam continuar com a inversão das atividades. }\end{array}$ \\
\hline A18 & $\begin{array}{l}\text { A proposta foi desenvolvida em período não especificado com dezoito (18) alunos da disci- } \\
\text { plina matemática de uma turma do } 9^{\circ} \text { ano do Ensino Fundamental II de uma escola estadual, } \\
\text { situada na zona central da cidade de Dom Pedrito/RS. Foi realizada uma análise textual } \\
\text { discursiva a partir dos dados produzidos nas atividades realizadas pelos estudantes, do diário } \\
\text { de bordo da professora/pesquisadora, e de um questionário realizado com a turma no final } \\
\text { das seis (6) aulas. A análise desses dados teve o objetivo de verificar como se mostra a } \\
\text { viabilidade das atividades onde foi trabalhada a Rotação por Estações no âmbito da Educação } \\
\text { Matemática Crítica. }\end{array}$ \\
\hline
\end{tabular}

A partir da análise dos trabalhos descritas no Quadro 2, embora não fosse objetivo específico da pesquisa, inicialmente foi percebido que não há uma unanimidade na escolha dos modelos de EH. Dos dezoito (18) trabalhos, oito (8) não atribuem as atividades realizadas a nenhum dos modelos anteriormente apresentados. Dos outros dez (10) restantes, quatro (4) apontaram a "Sala de aula invertida”, como o único modelo utilizado (artigos de Ref. A9, A11, A12 e A17), dois (2)“Rotação por estações" (A6 e A18), um (1) "Laboratório rotacional" (artigo A8). Alguns artigos empregaram mais de um modelo, por exemplo, o artigo de Ref. A2 utilizou os modelos "Rotação por Estações" e “Laboratório Rotacional”. Já o artigo A13, por sua vez, utilizou os modelos "Sala de aula Invertida" e "Rotação por Estações de Trabalho". Por último, o artigo A15 aplicou nas suas aulas os modelos "Sala de Aula Invertida”, “Rotação Individual”, "Laboratórios Rotacionais" e o "Modelo à La Carte".

Outro ponto a ser destacado é que apenas oito (8) dos dezoito (18) artigos aplicaram questionários, formulários ou entrevistas como ferramenta única de busca para validação do uso de modelos de ensino híbrido. No caso do artigo de referência 8 pode ser destacada a aplicação de formulários voltados para validar o uso do Laboratório Rotacional e para caracterizar as estratégias e 
LEMOS, F. C.; ALMEIDA JR, P. L. (2020) Avaliação docente no Ensino Híbrido

práticas pedagógicas que devem ser abordadas dentro do Ensino Híbrido. Já no artigo Ref. A9, pode ser destacada a aplicação do questionário voltado também ao tempo ideal para a duração de uma vídeo-aula. Por último, pode ser citada a pesquisa Ref. A10, na qual além de validar o uso da metodologia progressista, o questionário também avaliou o papel do docente.

Sobre os outros dez (10) artigos restantes, foi observado que além de buscar validar as propostas aplicadas em sala de aula, buscou-se, por exemplo, validar e/ou descrever o comportamento das turmas ao longo das aulas. No caso específico da pesquisa de referência A15 foi analisado o nível de engajamento dos estudantes ao longo da implementação do modelo híbrido. Nessa pesquisa, foi concluído que o engajamento cognitivo foi baixo, pois a maioria dos estudantes preferiu a "educação bancária", característica do modelo tradicional de ensino, no qual o docente deposita o conhecimento no aluno.

A respeito da última análise dos artigos voltada para a avaliação do trabalho docente e das habilidades docentes, foi percebido que apenas dois (2) artigos discutiram a respeito dessa análise. Esses artigos foram os de referência A8 e A10.

No artigo de referência A8, intitulado "Como Significar a Aprendizagem de Matemática Utilizando os Modelos de Ensino Híbrido", a avaliação do docente foi realizada dentro do mesmo formulário utilizado para outras atividades, disponível na Plataforma Educacional Khan Academy no qual todos os sujeitos responderam se concordavam ou discordavam da frase " $O$ planejamento do professor é fundamental para conduzir uma aula com o apoio das tecnologias". Ao avaliar o papel do professor no modelo de ensino híbrido Laboratório Rotacional, as autoras apontam que

“(...) a avaliação diagnóstica no Ensino Híbrido é fundamental para que as ações pedagógicas possam ser planejadas e direcionadas a partir da constatação das necessidades dos alunos, possibilitando identificar o percurso a ser traçado no planejamento dos roteiros a serem trabalhados, a fim de fornecer subsídios para o professor organizar suas ações (p. 18)."

A partir desse trecho, é possível perceber um alinhamento com as ideias de Hoffmann (2016), quando apontam que "o docente precisa de planejamento no qual saberá precisamente qual será seu papel em cada momento do processo e auxiliar seus educandos individualmente ou até mesmo em grupos." Não basta planejar as atividades do ponto de vista científico, é preciso conhecer as necessidades dos estudantes para desenvolver o percurso a partir delas.

Já em relação ao artigo de referência A10, cujo título é "Modelo de Ensino Híbrido: a percepção dos alunos em relação à Metodologia progressista x Metodologia tradicional”, a avaliação do docente foi realizada a partir de um questionário cujo propósito foi investigar a percepção dos alunos em relação ao perfil do professor (pontualidade, assiduidade e domínio do conteúdo ensinado), às metodologias de ensino/aprendizagem empregada pelos professores, à interação professor-aluno (incentivo à participação dos alunos e respeito), e por fim, quanto ao processo avaliativo (nível de avaliação adequado e métodos de avaliação). Após a análise dos resultados, os autores concluíram que "para a implementação de um modelo de ensino híbrido, é necessário muito mais do que apenas a utilização de recursos digitais. (...) é preciso um planejamento adequado, tanto para familiarizar os alunos com as ferramentas digitais, quanto para incorporá-las no contexto escolar (p. 115)". Já quanto ao processo avaliativo foi concluído que "para obter um bom resultado nas avaliações online, 
LEMOS, F. C.; ALMEIDA JR, P. L. (2020)

Avaliação docente no Ensino Híbrido

é necessário que os alunos tanto dominem o conteúdo específico, quanto saibam manipular as ferramentas digitais (p. 117)".

Nesses trechos novamente pode ser destacada a questão do planejamento citado por Hoffmann (2016) e da preocupação em aplicar ferramentas digitais que os estudantes consigam utilizar facilmente, principalmente no caso das avaliações, porque em alguns casos, o professor não poderá instruir o estudante com a atenção e tempo necessário. Ao tratar dessa instrução e avaliação, é possível fazer uma associação com Lima e Moura (2015) quando apontam que, se o propósito do professor é avaliar, ele deve escolher uma ferramenta eficiente no levantamento de dados para transformar feedback em orientação educacional.

No que cerne à avaliação da prática docente, outros três (3) artigos merecem destaque nesta discussão: artigos de referência A2, A6 e A7. No artigo de referência A2, intitulado "De mãos limpas com as tecnologias digitais", mesmo não havendo análise voltada para o papel do professor. Nas considerações finais, é destacada a necessidade de planejamento docente ao destacar que "professores devem se ater a planejamentos que também alcancem as pessoas com deficiência presentes no contexto da sala de aula. (p.18)". Observa-se que o planejamento deve "abraçar" a inclusão e buscar utilizar atividades contemplativas para cada caso de estudante com necessidades especiais.

No trabalho de referência A6, cujo título é "Leigos ou excluídos? A criação de um aplicativo educacional e seu uso via ensino híbrido em uma escola pública".

Observa-se que nos trechos como "A habilidade de aprender a personalizar o ensino, empregando atividades desenvolvidas com a tecnologia deve ser tomada como uma nova oportunidade educativa (p.20)" e "A título de sugestão, que os docentes interessados (...) estejam empenhados na realização de propostas de ensino-aprendizagem (...) que contemplem práticas de investigação e pesquisa (p.22)".

É possivel observar a estimulação da personificação do ensino, assim como, um planejamento voltado para a prática de investigação e pesquisa nos trechos, respectivamente. No caso da personificação, é possível fazer um paralelo conforme citado por Lima e Moura (2015), ao colocar que a ação docente no EH deve identificar problemas e agir com foco em individualizar e personalizar o ensino.

Por último, na pesquisa de referência A7 intitulada "O Ensino Híbrido como modalidade de interação ativa e reflexão crítica: relato de uma experiência docente no Brasil", também foi destacado o planejamento das atividades conforme destacado no trecho "O planejamento e a organização são características marcantes das formas de ensino mediadas por tecnologia que tenham como objetivo principal o amadurecimento escolar e acadêmico progressivo (p.17)."

\section{Conclusão}

$\mathrm{Na}$ abordagem do EH, é preciso ter ciência que, conforme apontado por Bacich, Tanzi Neto e Trevisani (2015), "não há uma ordem estabelecida para aplicação desses modelos em sala de aula e não há hierarquia entre eles." O modelo a ser escolhido depende de fatores como: o assunto a ser abordado, os objetivos a serem alcançados, do perfil da escola e da turma, das habilidades do professor, entre outros. 
LEMOS, F. C.; ALMEIDA JR, P. L. (2020) Avaliação docente no Ensino Híbrido

Em um contexto pós-pandemia do COVID 19, é importante destacar que essa modalidade de ensino deve continuar sendo aplicada equilibrando o ensino presencial com o online, demonstrando a importância do espaço formal de ensino para a construção do conhecimento, e possibilitando ao docente trabalhar todos os seus saberes. Nesse contexto, apesar de uma maior procura e espaço para o ensino online, o ensino presencial deve ser mantido de modo a ampliar a visão do conteúdo já apresentada na plataforma online, assim como, para evidenciar as suas aplicações e contextualizações.

Em relação ao levantamento dos artigos realizado no Portal de Periódicos da CAPES, foi possível perceber um crescimento da valorização desse termo nos artigos mais recentes. Para confirmar esse crescimento, observaram-se que nos cinco (5) primeiros meses de 2020, quatro (4) trabalhos foram publicados nessa fonte de busca, enquanto em 2010 havia sido apenas um (1). Em contrapartida, em 2019 apenas um (1) trabalho havia destacado a aplicação dessa modalidade em sala de aula, demonstrando assim, que dentro do banco de dados analisado, esses trabalhos não seguem um crescimento linear.

Já no que diz respeito às estratégias utilizadas para avaliar o trabalho docente foi concluído que ferramentas como questionários e entrevistas têm sido as mais recorrentes. Sobre a análise da coleta de dados a partir dessas ferramentas, verificaram-se que os pesquisadores ou discutiram as respostas dos alunos (Ref. A8) ou investigaram a percepção dos alunos em relação ao perfil do professor (Ref. A10).

Sobre as habilidades docentes, foram percebidas referências à formação e planejamento docente, de modo a dominar ferramentas digitais para instruir os estudantes em uma aula com o apoio das tecnologias, bem como, adequar as estratégias didáticas para abraçar a inclusão, a partir de atividades contemplativas para cada caso de estudante com necessidades especiais. Além disso, o docente deve ser capaz também de identificar problemas e agir com foco em individualizar e personalizar o ensino, bem como adequar a avaliação ao nível da turma.

Em relação ao planejamento e as habilidades, observou-se que é importante refletir onde as avaliações devem ser conduzidas no sentido de constatar as necessidades dos alunos. Além disso, houve referência à interação professor-aluno, na qual o docente deve estar apto a incentivar a participação dos alunos e a prezar pelo respeito.

A partir das estratégias utilizadas para avaliar a figura do professor e as habilidades docentes durante a aplicação de metodologias que envolvem o Ensino Híbrido, foi possível concluir ainda há necessidade de melhor categorizar as novas habilidades necessárias aos docentes que utilizam essas propostas de ensino.

De modo a contribuir com futuras pesquisas, podem ser sugeridas como categorias a serem avaliadas, a partir de Lemos (2016), as seguintes habilidades: a adequação do conteúdo para a turma; a capacidade de ouvir as colocações dos estudantes (de modo a fazer alterações, por exemplo nas rotações); capacidade de auxiliar os grupos na resolução de problemas e na construção de pensamento crítico; ter empatia para lidar com os sentimentos dos estudantes em diferentes momentos; buscar questionar os alunos e tentar observar se os mesmos estão compreendendo o assunto abordado assim como, conduzir experimentos, manusear equipamentos, acionar dispositivos 
LEMOS, F. C.; ALMEIDA JR, P. L. (2020)

Avaliação docente no Ensino Híbrido

tecnológicos ou utilizar Tecnologias de informação e comunicação (TIC's). A partir da análise criteriosa dessas habilidades, acredita-se ser possível trabalhar o Ensino Híbrido de maneira cada vez mais efetiva.

\section{Referências}

ANGELUCCI, C. B; KALMUS, J; PAPARELLI, RENATA e PATTO, M. H. S. O estado da arte da pesquisa sobre o fracasso escolar (1991-2002): um estudo introdutório. Educação e Pesquisa, 30: 51-72, 2004.

ANTONELLO NETO, A.P. A aplicação do Ensino híbrido na educação profissional e tecnológica: potencialidades e dificuldades. 92 p. Dissertação (Mestrado) - Universidade Federal de Santa Maria, Programa de Pós-graduação em Educação profissional e tecnológica, Santa Maria-RS, 2017.

BARION, E.C.N e MELLI, N.C.A. Algumas reflexões sobre o ensino híbrido na educação profissional. 2017. In: XII WORKSHOP DE PÓS-GRADUAÇÃO E PESQUISA DO CENTRO PAULA SOUZA. Saberes e práticas contemporâneas em gestão e inovação na Educação Profissional e em Sistemas Produtivos, 2017. Anais. São Paulo-SP, 2017.

BACICH, L.; TANZI NETO, A.; TREVISANI, F. M. (Org.). Ensino híbrido: personalização e tecnologia na educação. Porto Alegre: Penso, 2015.

CANDIDO JUNIOR, E. Ensino híbrido na educação superior: desenvolvimento a partir da base TPACK em uma perspectiva de metodologias ativas de aprendizagem. 166 p. Dissertação (mestrado) Universidade Estadual Paulista “Júlio de Mesquita Filho" (UNESP), Programa de Pós-Graduação em Educação, Presidente Prudente - SP, 2019.

CEMBRANEL, C.B e SCOPEL, J.M. Ensino híbrido e a construção da aprendizagem dos estudantes do ensino médio. SCIENTIA CUM INDUSTRIA, 7: 12- 15, 2019.

CERUTTI, E. e MELO, L.F. Abordagem híbrida no ensino superior: reflexões teórico-metodológicas. Revista on line de Política e Gestão Educacional, 21: 605-620, 2017.

CONSERVA, D.P e COSTA, M. A. M. O ensino de inglês permeado pela proposta de sala de aula invertida: um relato de experiência didática. ETD- Educação Temática Digital, 1: 234-252, 2020.

COSTA, H.B.A Problematizando práticas de ensino e aprendizagem na Plataforma Moodle: aproximações com a modalidade híbrida. Revista EntreLínguas, 2: 283-299, 2016.

FRANTZ, D.S.F.S; MARQUES, N.L,R; NUNES, J.F e MARQUES, I.L. Ensino Híbrido com a utilização da plataforma Moodle. Revista THELMA, 15: 1175-1186, 2018.

GUIMARÃES, D.S e JUNQUEIRA, S.M.S. Rotação por estações no trabalho com equações do $2^{\circ}$ grau: uma experiência na perspectiva do ensino híbrido. Revista Educação Matemática Pesquisa, 22: 708730, 2020.

HOFFMANN, E.H. Ensino híbrido no ensino fundamental: possibilidades e desafios. $44 \mathrm{f}$. Projeto de Trabalho de Conclusão de Curso - UFSC- Universidade Federal de Santa Catarina, Especialização em Educação na cultura digital, Florianópolis-SC, 2016.

HORN, M. B. e STAKER, H. Blended. Usando a inovação disruptiva para aprimorar a educação. 1.ed. Porto Alegre, Penso, 2015. 292 p.

KRAVISKI, M.R. Formar-se para formar: formação continuada de professores da educação superior em serviço - em metodologias ativas e ensino híbrido. 130 p. Dissertação (mestrado) - Centro Universitário Internacional (Uninter), Mestrado profissional em Educação e novas tecnologias, Curitiba - PB, 2019. 
LEMOS, F. C.; ALMEIDA JR, P. L. (2020) Avaliação docente no Ensino Híbrido

LEMOS, F.C; FERREIRA, H.S. Exposição Dengue: investigando as aprendizagens mobilizadas em museu de ciência. 130 f. Dissertação (mestrado) - UFRPE, Programa de Pós-graduação em Ensino de ciências, Recife, 2016.

LIMA, L. H. F e MOURA, F.R. O professor no ensino híbrido. In: BACICH, L; TANZI NETO, A.; TREVISANI, F. M. (Org.). Ensino Híbrido - personalização e tecnologia na educação. 1.ed. Porto Alegre, Penso, 2015. 203p.

MIRANDA, R.V; MORET, A. S; SILVA, J. C e SIMÃO, B. P. Ensino Híbrido: Novas habilidades docentes mediadas pelos recursos tecnológicos. Revista EaD em Foco, 1: 1-19, 2020.

NASCIMENTO, E.R; ANJOS, F.L.M.R; MENEZES, K.K.O e OLIVEIRA, G.B.L. Narrativas digitais para uma aprendizagem significativa no Ensino Superior qual a percepção dos estudantes? Educação Por Escrito, 9: 251-269, 2018.

NASCIMENTO, E.R e PADILHA, M.A.S. Learning by blended education in higher education: narrating the engagement of students. Revista Diálogo Educacional, 20: 252-271, 2020.

PALANCH, W.B. L e FREITAS, A. V. Estado da Arte como método de trabalho científico na área de Educação Matemática: possibilidades e limitações. Perspectivas da Educação Matemática, 8: 794-802, 2015.

PASIN, D.M e DELGADO, H.O.K. O ensino híbrido como modalidade de interação ativa e reflexão crítica: Relato de uma experiência docente no Brasil. Revista Texto Livre - Linguagem e Tecnologia, 10: p.87105, 2017.

PASSOS, M.L.S. MM-Híbrido - Modelo de Maturidade para Avaliação do Ensino Híbrido em Instituições de Ensino Superior. 237 f. Tese (doutorado) - Universidade Federal do Rio Grande do Sul, Programa de Pós-graduação em Engenharia de produção, Porto Alegre, 2018.

RABELL, C.R.L e TAVARES, K.C.A. Redes sociais e aprendizagem no ensino superior: a perspectiva dos alunos sobre o uso do Facebook em uma disciplina de língua inglesa. Veredas - Revista de Estudos Linguísticos, 20: 124-136, 2016.

RIBEIRO, L.C.V. Testando novas metodologias de aprendizagem para o ensino de embriologia humana: relato de experiência e percepção dos discentes. Revista Docência do Ensino Superior, 8: 151-165, 2018.

SANTOS, S.C.S. Ensino Híbrido em formação docente de curso de Biologia em uma disciplina em Instituição de Ensino Superior Pública. Revista Educitec, 4: 1-16, 2016.

SCHIEHL, E. P e GASPARINI, I. Contribuições do Google Sala de Aula para o Ensino Híbrido. Revista Novas Tecnologias na Educação, 14: 1-10, 2016.

SILVA, E. R. O Ensino Híbrido no Contexto das Escolas Públicas Brasileiras: Contribuições e Desafios. Revista Porto das Letras, 3: 1-18, 2017.

SILVA, J.B; SILVA, D.O e SALES, G.L. Modelo de Ensino Híbrido: a percepção dos alunos em relação à Metodologia progressista x Metodologia tradicional. Revista Conhecimento Online, 2: 103-118, 2018.

SIQUEIRA, L.M.M e TORRES, P.L. O ensino híbrido da eletricidade utilizando objetos de aprendizagem na engenharia. Cad. Bras. Ens. Fís., 27: 334-354, 2010.

SOUSA, Y.H; MENDONÇA A.P e COELHO, I.M.W.S. Uma proposta de ensino-aprendizagem de inglês para fins específicos baseada no Ensino híbrido. Revista EntreLínguas, 4: 165-181, 2018.

STEINERT, M.E.P e HARDOIM, E.L. Leigos ou excluídos? A criação de um aplicativo educacional e seu uso via ensino híbrido em uma escola pública. Revista SUSTINERE, 5: p. 90-113, 2017.

STEINERT, M.E.P; HARDOIM, E.L e PINTO, M.P.P.R.C. De mãos limpas com as tecnologias digitais. Revista 
LEMOS, F. C.; ALMEIDA JR, P. L. (2020) Avaliação docente no Ensino Híbrido

SUSTINERE, 4: 233-252, 2016.

STEINERT, M.E.P; BARROSA, M.P e PEREIRA, M. C. O Descompasso Entre Ensino Híbrido e Digital Divide: Docentes de Ciências da Natureza em Foco. Revista de Ensino, Educação e Ciências Humanas, 17, 209 215, 2016.

VALENTE, J. A. Blended learning e as mudanças no ensino superior: a proposta da sala de aula invertida. Educar em Revista, 4: 79-97, 2014.

VergarA, A. C. E; HINZ, V. T e LOPES, J. L. B. Como Significar a Aprendizagem de Matemática Utilizando os Modelos de Ensino Híbrido. Revista Thelma, 15: 885-904, 2018.

WAJNSZTEJN, M; ANDRÉ, C.F e AZEVEDO, A.B. Blended learning como estratégia de engajamento no ensino superior: relato de uma experiência de aprendizagem conectada, colaborativa e social. Revista EDaPECI, 20: 22-36, 2020. 